\title{
Short-term Risk of Revision THA in the Medicare Population Has Not Improved With Time
}

\author{
Kevin J. Bozic MD, MBA, Kevin Ong PhD, Steven Kurtz PhD, \\ Edmund Lau MS, Thomas P. Vail MD, Harry Rubash MD, \\ Daniel Berry MD
}

Received: 4 March 2015/ Accepted: 11 August 2015/Published online: 23 September 2015

(C) The Association of Bone and Joint Surgeons \& 2015

\begin{abstract}
Introduction Advances in surgical technique, implant design, and clinical care pathways have resulted in higher expectations for improved clinical outcomes after primary THA; however, despite these advances, it is unclear whether the risk of revision THA actually has decreased with time. Understanding trends in short- and mid-term risks of revision will be helpful in directing clinical, research, and policy efforts to improve THA outcomes.
\end{abstract}

One of the authors certifies that he (TPV), or a member of his or her immediate family, has received or may receive payments or benefits, during the study period-royalty for certain and hip and knee products, DePuy, USD 100,001 to USD 1,000,000. One of the authors certifies that he (DB), or a member of his or her immediate family, has received or may receive payments or benefits, during the study period-royalty for certain hip and knee implants, DePuy, USD 100,001 to USD $1,000,000$. One of the authors certifies that he (HR), or a member of his or her immediate family, has received or may receive payments or benefits, during the study period-USD 10,000 to USD 100,000 from Stryker/MAKO for Institutional Royalties, less than USD 10,000 from Ceramtec for consulting, less than USD 10,000 from Lippincott, Williams, \& Wilkins for royalties, less than USD 10,000 from Flexion Therapeutics for consulting, less than USD 10,000 from Pacira for consulting. One of the authors certifies that he (KJB), or a member of his or her immediate family, has received or may receive payments or benefits, during the study period-less than USD 10,000 from Institute for Healthcare Improvement for consulting, less than USD 10,000 from Harvard Business School for consulting, USD 10,000 to 100,000 from Centers for Medicare and Medicaid Services for consulting.

All ICMJE Conflict of Interest Forms for authors and Clinical Orthopaedics and Related Research ${ }^{\circledR}$ editors and board members are on file with the publication and can be viewed on request.

Clinical Orthopaedics and Related Research ${ }^{\mathbb{R}}$ neither advocates nor endorses the use of any treatment, drug, or device. Readers are encouraged to always seek additional information, including FDA approval status, of any drug or device before clinical use.

Each author certifies that the institution where the work was
Question/purposes We therefore asked (1) whether there have been changes in overall short- and mid-term risks of revision THA among patients in the Medicare population who underwent primary THA between 1998 and 2010; and (2) whether there are different demographic factors associated with short- and mid- term risks of revision THA. Methods Using the Medicare 5\% national sample database, patients who underwent primary THA between 1998 and 2010 followed by subsequent revision through 2011

performed approved the human protocol for this investigation and that all investigations were conducted in conformity with ethical principles of research.

This work was performed at the University of California, San Francisco, CA, USA.

\section{K. J. Bozic $(\bowtie)$}

Department of Surgery and Preoperative Care, Dell Medical School at University of Texas at Austin, 1912 Speedway, Suite 564, Sanchez Building, Austin, TX 78712, USA

e-mail: kevin.bozic@austin.utexas.edu

K. Ong, S. Kurtz

Exponent, Inc, Philadelphia, PA, USA

E. Lau

Exponent, Inc, Menlo Park, CA, USA

S. Kurtz, D. Berry

Department of Orthopaedic Surgery, Mayo Clinic, Rochester, MN, USA

T. P. Vail

Department of Orthopaedic Surgery, University of California, San Francisco, San Francisco, CA, USA

H. Rubash

Department of Orthopaedic Surgery, Massachusetts General Hospital, Boston, MA, USA 
were identified by ICD-9-CM procedure codes 81.51 and 81.53/80.05/00.70-00.73, respectively. This dataset included a random sample of Medicare beneficiaries based on their social security number. Only patients with minimum 1-year followup after primary THA were included in our analysis. A total of 64,260 patients who underwent primary THA were identified from the 1998 to 2010 Medicare 5\% dataset. Eighty-eight percent of the patients had 1-year followup providing a final study cohort of 56,700 patients. The risk of revision was evaluated at 1, 3, 5, and 7 years. Multivariate Cox regression was used to evaluate temporal trends in revision risk using two methods to account for time effects with periods 1998 to 2002, 2003 to 2007, and 2008 to 2010 for the index year of primary THA, and individual year of index of primary THA as independent variables. The analysis adjusted for patient age, sex, race, census region, Charlson score, and socioeconomic status.

Results The 7-year crude risk of revision THA declined from $7.10 \%$ in 1998 to 2002 to $6.09 \%$ in 2008 to 2010 , representing a $14.4 \%$ overall reduction in adjusted risk of revision $(\mathrm{p}=0.0058 ; 95 \% \mathrm{CI}, 4.4 \%-23 \%)$. Similarly, the 5year crude risk of revision THA declined from $5.96 \%$ in 1998 to 2002 to $5.11 \%$ in 2008 to 2010 , representing a $14.2 \%$ overall reduction in adjusted risk of revision $(\mathrm{p}=0.0069$; 95\% CI, $4.1 \%-23 \%$ ). However, the adjusted risk of revision THA at 3 years was not different from 1998 to 2002 (4.70\%) and 2008 to 2010 (4.03\%; p = 0.1176). Similarly, the adjusted risk of revision at 1 year did not differ from 1998 to $2002(2.83 \%)$ and 2008 to $2010(2.42 \% ; \mathrm{p}=0.3386)$. Patients with more comorbidities had a greater adjusted risk of revision ( $\mathrm{p}<0.001)$ at all times: $94 \%(95 \% \mathrm{CI}, 58 \%-138 \%)$ and $56 \%(95 \% \mathrm{CI}, 33 \%-84 \%)$ at 1 year and 7 years, respectively, for Charlson score of 5+ vs 0 ).

Conclusions Although the mid-term (5 and 7 years) risk of revision THA has decreased during the past 14 years among Medicare beneficiaries who underwent primary THA, the short-term risk has not. These findings suggest that greater clinical, research, and policy emphasis is needed to identify potentially avoidable causes of early failure after primary THA in patients in the Medicare population, and multistakeholder solutions are needed to optimize short-term outcomes.

Level of Evidence Level III, therapeutic study.

\section{Introduction}

Advances in surgical technique, implant design, and clinical care pathways have resulted in greater expectations for improved clinical outcomes after primary THA. The national joint replacement registries in Scandinavia show that 10-year revision rates decreased with time in the 1990s and 2000s, which has been attributed to the positive

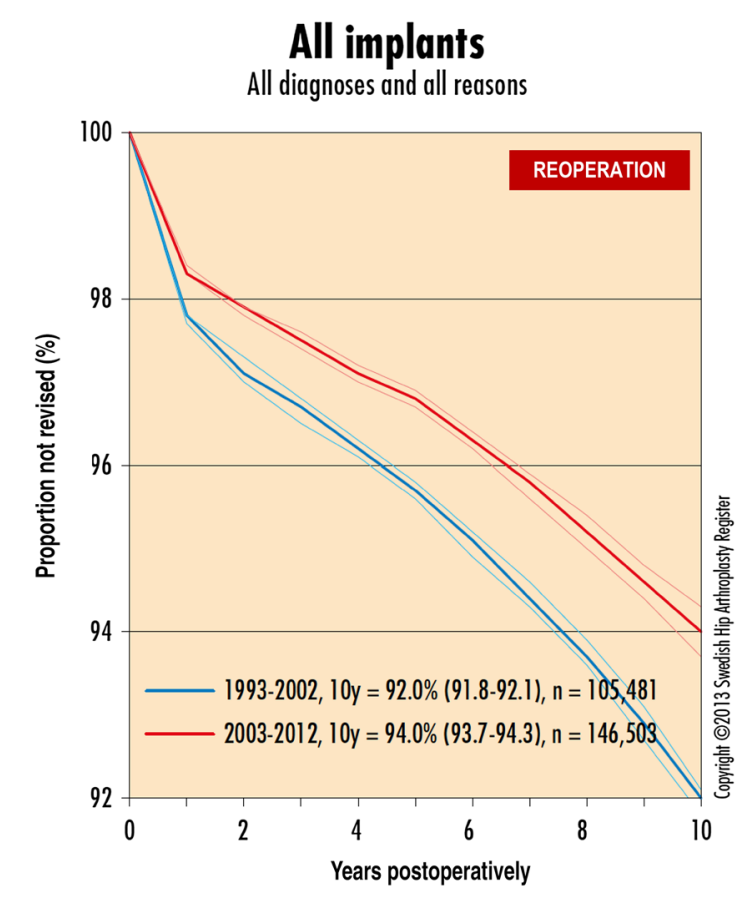

Fig. 1 The Kaplan-Meier estimates of cumulative percentage probability of survivorship for 1993 to 2002 compared with 2003 to 2012 are shown. (Reprinted with permission from The Swedish Hip Arthroplasty Register. Garellick G, Rogmark C, Karrholm J, Rolfson O. Annual Report 2012. http://www.shpr.se/Libraries/Documents/ AnnualReport_2012_Eng_WEB.sflb.ashx.)

feedback provided by the registry on the practice of orthopaedic surgery (Fig. 1). However, it is uncertain if that trend will persist when comparing surgeries performed at the beginning and end of the 2000s. Despite the vigilance of an active registry in the UK, the latest report suggests that revision rates increased between 2003 and 2008 [28], which has been attributed to the use of certain metal-on-metal bearings (Fig. 2).

Thus, despite the evolutionary changes in THA implant technology that have been introduced during the past two decades, it is unclear whether the risk of revision has changed with time in the United States. Furthermore, compared with primary THAs, revision THAs are associated with increased risk of complications including periprosthetic joint infection and dislocation [3, 4, 21]. Revision THAs are an economic burden on the Medicare system; 19\% of Medicare reimbursements are for revision THAs [31]. Therefore, it is important to clarify specifically where clinicians and policymakers should focus their care redesign and policy efforts to optimize THA outcomes.

We therefore asked (1) whether there has been a change in the overall short- and mid-term risks of revision THAs among patients in the Medicare population who underwent primary THA between 1998 and 2010; and (2) whether there are different demographic factors associated with short- and mid-term risks of revision THA. 


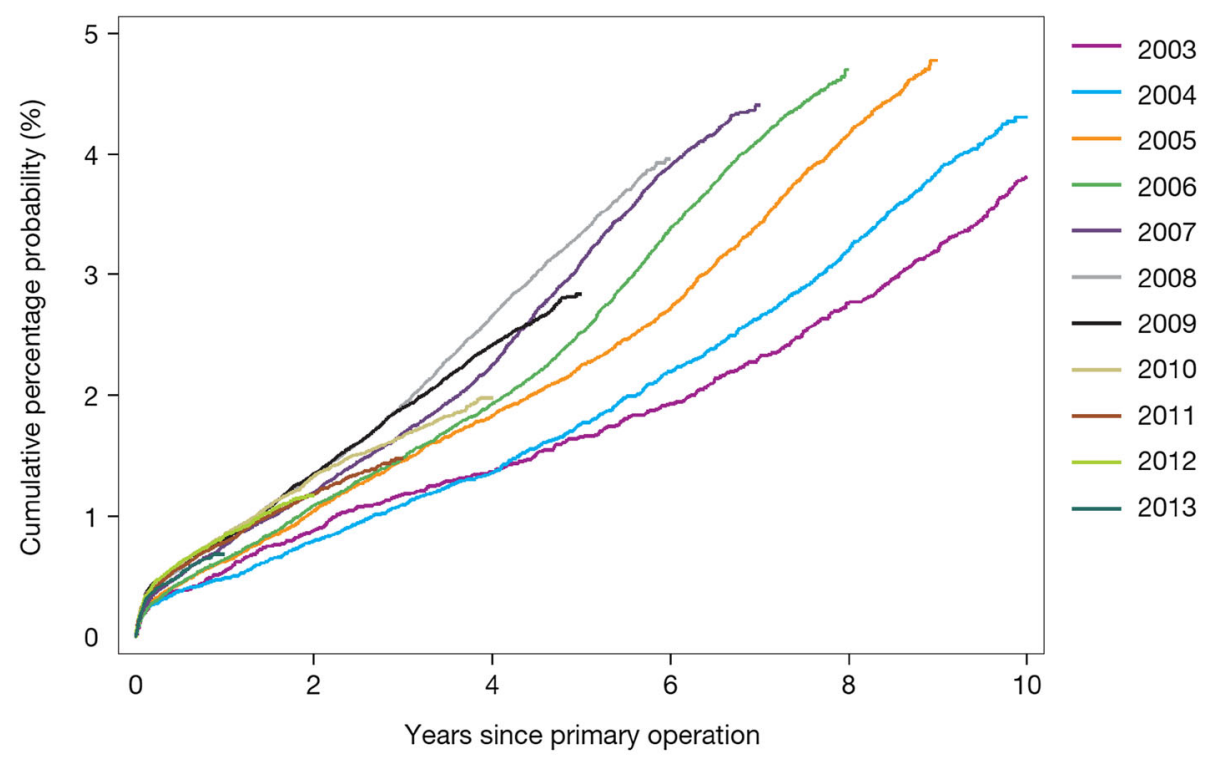

(CNational Joint Registry 2014

Fig. 2 Kaplan-Meier estimates of cumulative percentage probability of revision for each year of primary surgery are shown. (Reprinted with permission from the National Joint Registry of England, Wales

\section{Methods}

The 5\% sample of the Centers for Medicare \& Medicaid Services Medicare data [8] from 1998 to 2010 was used to identify patients who had undergone primary THA. An additional year of data from 2011 was included to provide followup of patients who underwent surgery in 2010. The $5 \%$ sample was created based on selecting records with 05 , 20, 45, 70, or 95 in Positions 8 and 9 of the Health Insurance Claim number. Thus, this dataset included a random sample of Medicare beneficiaries based on their social security number. Procedures were identified using ICD-9-CM code 81.51 from the Part A (inpatient) claims data. Each patient in the dataset was provided with an encrypted, unique beneficiary identifier to allow followup from time of enrollment in Medicare through death. Patients who were younger than 65 years were excluded owing to their enrollment in Medicare from their physical disabilities, such as end-stage renal disease or amyotrophic lateral sclerosis. Enrollees of health maintenance organizations, those not enrolled in Medicare Parts A and B, nonUS residents, and patients with less than a 12-month prior claim history before primary THA also were excluded from our study. These patients were excluded owing to an incomplete claim history. Patients who did not have at least 1 year followup after primary THA also were excluded, removing $12 \%$ of the cohort from the analysis.

A total of 64,260 patients older than 65 years who underwent primary THA and were insured by Medicare, and Northern Ireland. $11^{\text {th }}$ Annual Report 2014. Part 3. Outcomes after joint replacement 2003 to 2013.)

with a complete claim history, initially were identified from the 1998 to 2010 Medicare 5\% dataset. After requiring a minimum followup of 1 year, a final cohort of 56,700 patients remained. Of these patients, $65 \%$ were women, $50 \%$ were 54 to 74 years old, $94 \%$ were white, and $7 \%$ were of lower socioeconomic status, requiring state subsidy for their Medicare premium (ie, state "buy-in") (Table 1). Of the 56,700 patients who underwent primary THA, 3336 (6\%) underwent revision THA during the study period.

For the patients we included, the need to undergo revision surgery and/or arthrotomy was identified using ICD-9CM codes 81.53, 00.70-00.73, and 80.05. The demographic characteristics for the patients were evaluated. The risk of revision was evaluated at $1,3,5$, and 7 years. Multivariate Cox regression was used to evaluate temporal trends in revision risk using two methods to account for time effects. One approach used time when the patients underwent primary THA (1998 to 2002; 2003 to 2007, and 2008 to 2010 groups) as an independent variable in the analysis. The second approach was to consider the individual year of index primary THA as an independent variable. After the initial Cox model was fitted with year as a covariate, the model was used to estimate survival multiple times, each time assuming a different value for "year" from 1997 to 2010. Survival was estimated for each record in the data and an average value was calculated. The effect of any particular year, no different from any other covariate effect, is a multiplier to the survival function, and survival at any duration can be calculated with the "year" factor 
Table 1. Patient demographics*

\begin{tabular}{|c|c|c|c|c|}
\hline \multirow[t]{2}{*}{ Demographic group } & \multicolumn{2}{|c|}{ Without revision } & \multicolumn{2}{|c|}{ With revision } \\
\hline & Number & $\%$ of demographic subgroup & Number & $\%$ of demographic subgroup \\
\hline \multicolumn{5}{|l|}{ Sex } \\
\hline Men & 18,840 & 94.2 & 1154 & 5.8 \\
\hline Women & 34,524 & 94.1 & 2182 & 5.9 \\
\hline \multicolumn{5}{|l|}{ Age, years } \\
\hline $65-69$ & 12,070 & 93.0 & 909 & 7.0 \\
\hline $70-74$ & 14,475 & 93.7 & 970 & 6.3 \\
\hline $75-79$ & 13,538 & 94.3 & 825 & 5.7 \\
\hline $80-84$ & 9018 & 95.1 & 463 & 4.9 \\
\hline $85+$ & 4263 & 96.2 & 169 & 3.8 \\
\hline \multicolumn{5}{|l|}{ Race } \\
\hline White & 50,284 & 94.1 & 3147 & 5.9 \\
\hline Black & 2272 & 94.0 & 146 & 6.0 \\
\hline Other & 808 & 94.9 & 43 & 5.1 \\
\hline \multicolumn{5}{|l|}{ Census region } \\
\hline Midwest & 16,201 & 94.3 & 979 & 5.7 \\
\hline Northeast & 10,137 & 95.0 & 539 & 5.0 \\
\hline South & 17,841 & 93.9 & 1166 & 6.1 \\
\hline West & 9185 & 93.4 & 652 & 6.6 \\
\hline \multicolumn{5}{|l|}{ Charlson score } \\
\hline 0 & 18,110 & 94.1 & 1142 & 5.9 \\
\hline $1-2$ & 22,564 & 94.3 & 1371 & 5.7 \\
\hline $3-4$ & 9166 & 94.0 & 580 & 6.0 \\
\hline $5+$ & 3524 & 93.5 & 243 & 6.5 \\
\hline \multicolumn{5}{|l|}{ Buy-in status } \\
\hline With & 3797 & 94.0 & 241 & 6.0 \\
\hline Without & 49,567 & 94.1 & 3095 & 5.9 \\
\hline
\end{tabular}

* All patients underwent primary THA and did or did not undergo subsequent revision during the study period.

taking on any value of interest. The analysis adjusted for patient age, sex, race, census region, Charlson score, and socioeconomic status. Patient comorbidity history was evaluated based on diagnosed conditions in the 12 months before the primary THA. The Charlson comorbidity index predicts the 10-year mortality for a patient who may have a range of comorbid conditions. Each condition is assigned a score of $1,2,3$, or 6 , depending on the risk of dying associated with each condition. Scores are summed to provide a total score to predict mortality. Patients were categorized in one of four comorbidity grades: $0,1-2,3-4$, and 5 or more.

\section{Results}

After adjusting for demographic factors, the 7-year risks of revision THA declined by $14.4 \%$ in 2008 to 2010 (p = $0.0058 ; 95 \%$ CI, $4.4 \%-23 \%$ ) and by $13.4 \%$ in 2003 to 2007
( $\mathrm{p}<0.001 ; 95 \%$ CI, 6.0\%-20\%), compared with 1998 to 2002 (Table 2). Similarly, the 5-year adjusted risks of revision THA declined by $14.2 \%(\mathrm{p}=0.0069 ; 95 \% \mathrm{CI}$, $4.1 \%-23 \%)$ and by $12.8 \%(\mathrm{p}=0.0016 ; 95 \% \mathrm{CI}, 5 \%-20 \%)$ in 2008 to 2010 and 2003 to 2007, respectively, compared with 1998 to 2002. Although there was a downward trend with time (Fig. 3), the adjusted risks of revision THA at 1 year and 3 years were not associated with time $(p=0.3386$ at 1 year; $\mathrm{p}=0.1176$ at 3 years).

Patients with increasing numbers of comorbidities in terms of greater Charlson score had greater adjusted risk of revision $(\mathrm{p}<0.0001)$ at all times. Specifically, patients with a Charlson score of $5+$ had a $94 \%$ (95\% CI, 58\%$138 \%$ ) greater risk at 1 year and $56 \%$ (95\% CI, 33\%-84\%) greater risk at 7 years compared with patients with a score of 0 . Younger patients (65-69 years) also had greater adjusted risk of revision than patients 85 years and older at 3,5 , and 7 years $(\mathrm{p}<0.001)$, but not at 1 year $(\mathrm{p}=0.4216)$. Specifically, patients 85 years and older had a $32 \%$ lower 
Table 2. Kaplan-Meier risk of revision at $1,3,5$, and 7 years postprimary THA

\begin{tabular}{lllll}
\hline Year & 1 year $(95 \% \mathrm{CI})$ & 3 years $(95 \% \mathrm{CI})$ & 5 years $(95 \% \mathrm{CI})$ & 7 years $(95 \% \mathrm{CI})$ \\
\hline $1998-2002$ & $2.83(2.63 \%-3.02 \%)$ & $4.70(4.42 \%-4.98 \%)$ & $5.96(5.62 \%-6.29 \%)$ & $7.10(6.72 \%-7.48 \%)$ \\
$2003-2007$ & $2.44(2.28 \%-2.61 \%)$ & $4.07(3.83 \%-4.30 \%)$ & $5.16(4.88 \%-5.44 \%)$ & $6.15(5.82 \%-6.48 \%)$ \\
$2008-2010$ & $2.42(2.20 \%-2.63 \%)$ & $4.03(3.68 \%-4.37 \%)$ & $5.11(4.66 \%-5.55 \%)$ & $6.09(5.55 \%-6.63 \%)$ \\
1998 & $3.14(2.76 \%-3.51 \%)$ & $5.22(4.63 \%-5.81 \%)$ & $6.62(5.88 \%-7.35 \%)$ & $7.89(7.02 \%-8.74 \%)$ \\
1999 & $2.92(2.56 \%-3.27 \%)$ & $4.86(4.29 \%-5.42 \%)$ & $6.16(5.46 \%-6.86 \%)$ & $7.34(6.52 \%-8.16 \%)$ \\
2000 & $3.27(2.90 \%-3.65 \%)$ & $5.45(4.85 \%-6.04 \%)$ & $6.90(6.17 \%-7.64 \%)$ & $8.22(7.35 \%-9.08 \%)$ \\
2001 & $2.42(2.11 \%-2.73 \%)$ & $4.04(3.54 \%-4.53 \%)$ & $5.13(4.51 \%-5.74 \%)$ & $6.12(5.39 \%-6.84 \%)$ \\
2002 & $2.48(2.17 \%-2.79 \%)$ & $4.14(3.64 \%-4.62 \%)$ & $5.25(4.64 \%-5.86 \%)$ & $6.26(5.54 \%-6.98 \%)$ \\
2003 & $2.61(2.31 \%-2.92 \%)$ & $4.36(3.87 \%-4.85 \%)$ & $5.54(4.93 \%-6.14 \%)$ & $6.60(5.88 \%-7.31 \%)$ \\
2004 & $2.52(2.22 \%-2.82 \%)$ & $4.20(3.72 \%-4.67 \%)$ & $5.33(4.74 \%-5.92 \%)$ & $6.36(5.66 \%-7.05 \%)$ \\
2005 & $2.19(1.90 \%-2.47 \%)$ & $3.65(3.19 \%-4.11 \%)$ & $4.64(4.06 \%-5.21 \%)$ & $5.54(4.85 \%-6.21 \%)$ \\
2006 & $2.14(1.84 \%-2.44 \%)$ & $3.57(3.09 \%-4.05 \%)$ & $4.54(3.94 \%-5.14 \%)$ & $\mathrm{n} / \mathrm{a}$ \\
2007 & $2.72(2.37 \%-3.08 \%)$ & $4.54(3.98 \%-5.10 \%)$ & $5.76(5.06 \%-6.47 \%)$ & $\mathrm{n} / \mathrm{a}$ \\
2008 & $2.18(1.85 \%-2.51 \%)$ & $3.64(3.11 \%-4.17 \%)$ & $\mathrm{n} / \mathrm{a}$ & $\mathrm{n} / \mathrm{a}$ \\
2009 & $2.55(2.18 \%-2.91 \%)$ & $4.25(3.65 \%-4.84 \%)$ & $\mathrm{n} / \mathrm{a}$ & $\mathrm{n} / \mathrm{a}$ \\
2010 & $2.57(2.16 \%-2.97 \%)$ & $\mathrm{n} / \mathrm{a}(5 / \mathrm{a}$ & \\
\hline
\end{tabular}

$\mathrm{n} / \mathrm{a}=$ not available.

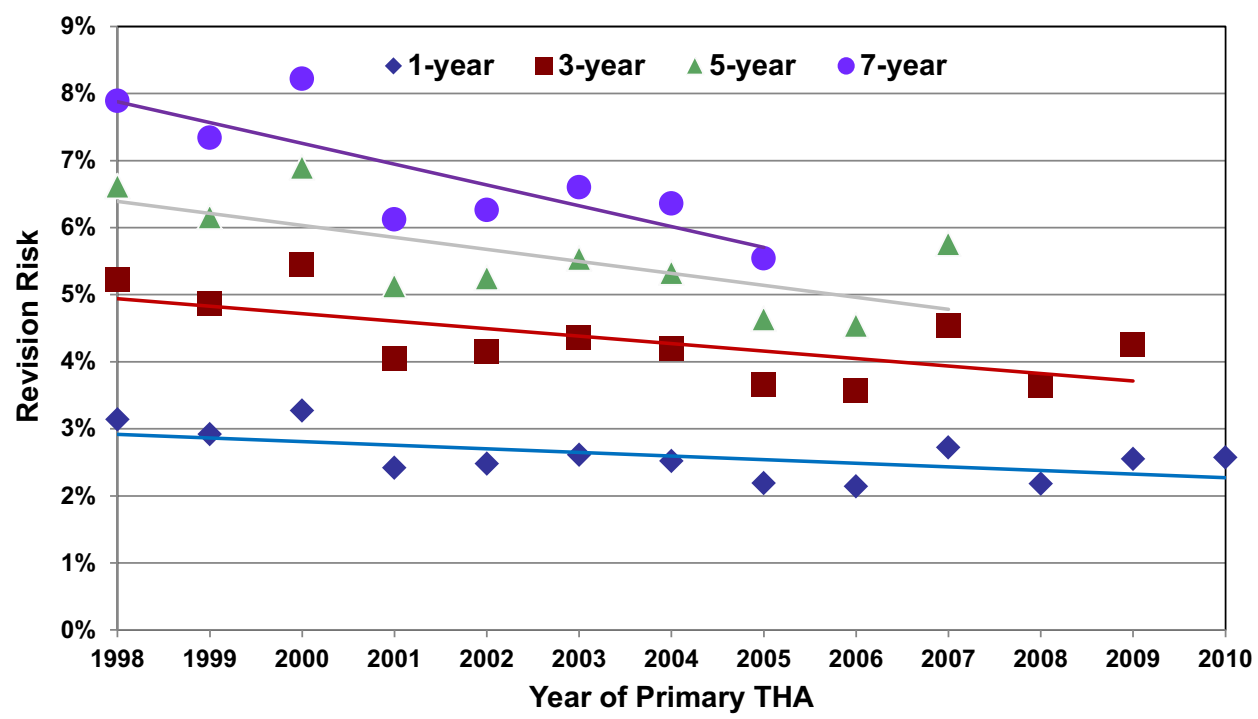

Fig. 3 Trends in the revision risk at 1, 3, 5, and 7 years after the primary THA based on year of primary THA are shown.

risk $(95 \% \mathrm{CI}, 18 \%-43 \%)$ at 3 years, 34\% lower risk $(95 \%$ $\mathrm{CI}, 22 \%-45 \%)$ at 5 years, and $35 \%$ lower risk $(95 \% \mathrm{CI}$, $23 \%-45 \%)$ at 7 years than patients 65 to 69 years old.

\section{Discussion}

Using the 5\% sample of Centers for Medicare \& Medicaid Services Medicare data from 1998 to 2011 [8], we found that although the mid-term ( 5 and 7 years) risk of revision THA has decreased during the past 14 years among patients in the Medicare population who underwent primary THA, the short-term risk has not. There are many potential reasons why we have made little progress in reducing the short-term risk of revision THA, including an increasing prevalence of patient comorbidities, which are known to influence short-term outcomes. Short-term risk of complications and revision THA among patients in the 
Medicare population were reported to be similar regardless of type of bearing surface [7], and patient-related risk factors, such as depression, rheumatologic disease, psychoses, renal disease, chronic urinary tract infection, and congestive heart failure were associated with an increased risk of revision THA within a year of index arthroplasty [5]. Furthermore, Dy et al. [13] found that health systemrelated factors (including Medicaid insurance and hospital procedure volumes) were associated with a higher risk of early revision THA. Collectively, these findings suggest that despite the progress we have made in reducing midterm revision rates as a result of improved implant design, work remains to be done to reduce short-term revision rates among the Medicare population undergoing THA.

This study has a several limitations. First the study was limited to only Medicare beneficiaries. Although Medicare beneficiaries represent the majority of US patients who undergo primary or revision THA, further study is necessary to better understand whether these trends are generalizable to patients who are younger than 65 years who undergo primary THA, who historically have poorer outcomes [10, 16]. Second, we relied on administrative claims data for our analysis which has inherent limitations that have been described [2, 19]. However, until large-scale data from a nationally representative total joint replacement registry are published and available for use in outcome research, administrative claims data remain the most useful source of data to evaluate longitudinal risk of revision among patients undergoing total joint replacement. Finally, owing to the time between clinical events, such as revision THA and availability of administrative claims data files for health services research, the most recent time we have available to analyze risk of revision THA is for patients who underwent surgery through 2010. Future studies will need to evaluate the risk of revision THA for patients who underwent surgery from 2011 to 2014, when the rate of revision THA for some patients with metal-onmetal bearings increased substantially [6].

Our study has important implications for future research and performance improvement efforts in THAs. Historically, factors related to limitations in implant design and/or manufacturing, including bearing surface wear, osteolysis, and mechanical loosening of the prosthesis, were the primary reasons for revision THA [11, 17, 18]. Owing to technologic and manufacturing advances, better implants and biomaterials have been developed to improve implant longevity [15, 32, 33]. The reduction in 5- and 7-year adjusted risks of revision THA likely reflects improvements in THA technology, such as large-diameter femoral heads which may have contributed to a reduction in the risk of dislocation, and the introduction of highly cross-linked polyethylene bearings, which have substantially reduced the risk of wear and osteolysis [15, 22, 25, 33]. However, despite these advances in implant technology, the shortterm ( 1 and 3 years) adjusted risk of revision THA has not declined. The causes of short-term revision THA (periprosthetic joint infection, dislocation, periprosthetic fracture) generally are more closely related to the quality of care delivered by the surgical and perioperative team, rather than limitations in implant design, with a few notable exceptions [1, 9, 14, 23, 24]. Little progress has been made during the past two decades in reducing the risk of periprosthetic joint infections despite increased awareness of the risk factors and importance [26]. Thus, improvement in implant designs that will enhance "implant longevity", the primary endpoint measured in most international registries, will not help in achieving the collective goal of improving patient outcomes, particularly with respect to short-term revision rates, which have the most substantial effect on overall THA outcomes. Therefore, future efforts in clinical care, research, and policy efforts should be focused on identifying multistakeholder strategies to reduce the risk of periprosthetic joint infections, dislocations, and other potentially avoidable causes of early revision THA. Such strategies could include increased emphasis on preoperative optimization of risk factors for periprosthetic joint infections, appropriate use and discontinuation of prophylactic antibiotics, reduced surgical times, improved surgical training through the use of surgical simulators, and perhaps tools to help surgeons improve the accuracy of acetabular cup placement during primary THA [12, 20, 34]. This places additional responsibility on the surgeon(s) and the surgical or hospital team to improve these outcomes.

The risk of revision THA in the Medicare population also should be considered in the context of recent guidance from the National Institute for Health and Care Excellence, a health authority in the United Kingdom [27, 29]. In 2000, they recommended the use of hip implants that had revision rates of $10 \%$ or less at 10 years, or, as a minimum, a 3-year revision rate consistent with this, that is, 3\% [30]. However, they recently indicated that revision rates of THA implants were lower than this historic guideline, and therefore they revised the recommendation, stating that "a new benchmark lower than $10 \%$ at 10 years would now appear appropriate for total hip replacement prostheses," even recommending the use of implants with rates of $5 \%$ or less at 10 years (annualized at 0.5\%) [27, 29]. Our study similarly confirmed that the historic mid-term (5 and 7 years) revision risk for patients in the Medicare population with primary THAs has declined with time; however, we found an average annual revision risk of approximately $0.8 \%$ based on the most recent 7 -year revision risk, which is substantially higher than the revised National Institute for Health and Care Excellence recommendation. Furthermore, we reported a 1-year revision risk in the 
Medicare population of approximately $2 \%$, which also is substantially greater than the original and recently proposed National Institute for Health and Care Excellence recommendation. The risk of revision THA in the United States is further elevated when younger patients are considered; they have been shown to be at greater risk of revision than elderly patients [10, 16]. Therefore, our findings from the Medicare cohort are not entirely consistent with the observations and recommendations by the National Institute for Health and Care Excellence for acceptable risk of revision THA in the United Kingdom. However, there are other considerations that make it difficult to define the acceptable risk of revision THA, including infection. As one of the most common indications for revision THA, infection is unlikely to be related to implant choice, and reasons for revision change as a function of time [4]. It may be more appropriate to define the acceptable risk of revision based on implant-related factors.

We found that the adjusted 5- and 7-year risks of revision THA among the Medicare population with primary THAs decreased substantially between 2003 and 2010, which may be attributable to improvements in implant design. However, the adjusted 1- and 3-year risks of revision THAs did not decrease during the same time. These findings suggest that greater emphasis is needed to identify and mitigate potentially avoidable causes of early revision after primary THA in the Medicare population, including implementation of multidisciplinary care delivery models, greater coordination of care across care delivery sites (eg, outpatient, inpatient, and postacute care), and increased emphasis on outcomes measurement.

Acknowledgments We thank Long-Co Nguyen BA, BS, (University of California, San Francisco, School of Medicine, San Francisco, CA, USA) and Lauren Uhler MPH (Department of Surgery and Perioperative Care, Dell Medical School at University of Texas at Austin, Austin, TX, USA) for assistance in preparing this manuscript.

\section{References}

1. Blumenfeld TJ, Bargar WL. Early aseptic loosening of a modern acetabular component secondary to a change in manufacturing. $J$ Arthroplasty. 2006;21:689-695.

2. Bozic KJ, Chiu VW, Takemoto SK, Greenbaum JN, Smith TM, Jerabek SA, Berry DJ. The validity of using administrative claims data in total joint arthroplasty outcomes research. J Arthroplasty. 2010;25(6 suppl):58-61.

3. Bozic KJ, Kurtz SM, Lau E, Ong K, Chiu V, Vail TP, Rubash HE, Berry DJ. The epidemiology of revision total knee arthroplasty in the United States. Clin Orthop Relat Res. 2010;468:45-51.

4. Bozic KJ, Kurtz SM, Lau E, Ong K, Vail TP, Berry DJ. The epidemiology of revision total hip arthroplasty in the United States. J Bone Joint Surg Am. 2009;91:128-133.
5. Bozic KJ, Lau E, Ong K, Chan V, Kurtz S, Vail TP, Rubash HE, Berry DJ. Risk factors for early revision after primary total hip arthroplasty in Medicare patients. Clin Orthop Relat Res. 2014;472:449-454.

6. Bozic KJ, Lau EC, Ong KL, Vail TP, Rubash HE, Berry DJ. Comparative effectiveness of metal-on-metal and metal-onpolyethylene bearings in Medicare total hip arthroplasty patients. J Arthroplasty. 2012;27(8 suppl):37-40.

7. Bozic KJ, Ong K, Lau E, Kurtz SM, Vail TP, Rubash HE, Berry DJ. Risk of complication and revision total hip arthroplasty among Medicare patients with different bearing surfaces. Clin Orthop Relat Res. 2010;468:2357-2362.

8. Centers for Medicare and Medicaid Services. Standard Analytical Files - LDS. Available at: https://www.cms.gov/Research-StatisticsData-and-Systems/Files-for-Order/LimitedDataSets/StandardAnalyti calFiles.html. Accessed August 7, 2015.

9. Chmell MJ, Poss R, Thomas WH, Sledge CB. Early failure of Hylamer acetabular inserts due to eccentric wear. J Arthroplasty. 1996;11:351-353.

10. Corbett KL, Losina E, Nti AA, Prokopetz JJ, Katz JN. Population-based rates of revision of primary total hip arthroplasty: a systematic review. PloS One. 2010;5:e13520.

11. Delaunay C, Hamadouche M, Girard J, Duhamel A, SoFCOT Group. What are the causes for failures of primary hip arthroplasties in France? Clin Orthop Relat Res. 2013;471:3863-3869.

12. Domb BG, El Bitar YF, Sadik AY, Stake CE, Botser IB. Comparison of robotic-assisted and conventional acetabular cup placement in THA: a matched-pair controlled study. Clin Orthop Relat Res. 2014;472:329-336.

13. Dy CJ, Bozic KJ, Pan TJ, Wright TM, Padgett DE, Lyman S. Risk factors for early revision after total hip arthroplasty. Arthritis Care Res (Hoboken). 2014;66:907-915.

14. Fernandez-Valencia J, Gallart X, Bori G, Ramiro SG, Combalia A, Riba J. Assessment of patients with a DePuy ASR metal-onmetal hip replacement: results of applying the Guidelines of the Spanish Society of Hip Surgery in a tertiary referral hospital. Adv Orthop. 2014;2014:982523.

15. Gomez-Barrena E, Medel F, Puertolas JA. Polyethylene oxidation in total hip arthroplasty: evolution and new advances. Open Orthop J. 2009;3:115-120.

16. Hailer NP, Garellick G, Karrholm J. Uncemented and cemented primary total hip arthroplasty in the Swedish Hip Arthroplasty Register. Acta Orthop. 2010;81:34-41.

17. Harris WH. Osteolysis and particle disease in hip replacement: a review. Acta Orthop Scand. 1994;65:113-123.

18. Harris WH. The problem is osteolysis. Clin Orthop Relat Res. 1995;311:46-53.

19. Hawker GA, Coyte PC, Wright JG, Paul JE, Bombardier C. Accuracy of administrative data for assessing outcomes after knee replacement surgery. J Clin Epidemiol. 1997;50:265-273.

20. Kanawade V, Dorr LD, Banks SA, Zhang Z, Wan Z. Precision of robotic guided instrumentation for acetabular component positioning. J Arthroplasty. 2015;30:392-397.

21. Khatod M, Barber T, Paxton E, Namba R, Fithian D. An analysis of the risk of hip dislocation with a contemporary total joint registry. Clin Orthop Relat Res. 2006;447:19-23.

22. Kurtz SM, Gawel HA, Patel JD. History and systematic review of wear and osteolysis outcomes for first-generation highly crosslinked polyethylene. Clin Orthop Relat Res. 2011;469:2262-2277.

23. Langton DJ, Jameson SS, Joyce TJ, Gandhi JN, Sidaginamale R, Mereddy P, Lord J, Nargol AV. Accelerating failure rate of the ASR total hip replacement. J Bone Joint Surg Br. 2011;93:10111016.

24. Livingston BJ, Chmell MJ, Spector M, Poss R. Complications of total hip arthroplasty associated with the use of an acetabular 
component with a Hylamer liner. J Bone Joint Surg Am. 1997;79:1529-1538.

25. Malkani AL, Ong KL, Lau E, Kurtz SM, Justice BJ, Manley MT. Early- and late-term dislocation risk after primary hip arthroplasty in the Medicare population. J Arthroplasty. 2010;25(6 suppl):21-25.

26. Matar WY, Jafari SM, Restrepo C, Austin M, Purtill JJ, Parvizi J. Preventing infection in total joint arthroplasty. J Bone Joint Surg Am. 2010;92(suppl 2):36-46.

27. National Institute for Health and Care Excellence. Overview: Total hip replacement and resurfacing arthroplasty for treating pain or disability resulting from end stage arthritis of the hip (review of technology appraisal guidance 2 and 44). Available at: http://www. fdanews.com/ext/resources/files/11/11-04-13-hips.pdf. Accessed June 11, 2015.

28. National Joint Registry of England, Wales and Northern Ireland. $11^{\text {th }}$ Annual Report 2014. Part 3. Outcomes after joint replacement 2003 to 2013. Available at: http://www.njrreports.org.uk/ Portals/0/PDFdownloads/NJR\%2011th\%20Annual\%20Report\%2 02014.pdf).

29. NICE. National Institute for Health and Care Excellence. Total hip replacement and resurfacing arthroplasty for end-stage arthritis of the hip (review of technology appraisal guidance 2 and 44). Available at: http://www.nice.org.uk/guidance/ta304/resources/ guidance-total-hip-replacement-and-resurfacing-arthroplasty-forendstage-arthritis-of-the-hip-review-of-technology-appraisal-guid ance-2-and-44-pdf Accessed December 27, 2014.

30. NICE, National Institute for Health and Care Excellence. Guidance on the selection of prostheses for primary total hip replacement. NICE technology guidance [TA2]. Available at: http://www.nice.org.uk/guidance/ta2. Accessed June 10, 2015.

31. Ong KL, Mowat FS, Chan N, Lau E, Halpern MT, Kurtz SM. Economic burden of revision hip and knee arthroplasty in Medicare enrollees. Clin Orthop Relat Res. 2006;446:22-28.

32. Ries MD. Review of the evolution of the cementless acetabular cup. Orthopedics. 2008;31(12 suppl 2): pii: 1orthosupersite.com/ view.asp?rID $=37178$.

33. Sobieraj MC, Rimnac CM. Ultra high molecular weight polyethylene: mechanics, morphology, and clinical behavior. $J$ Mech Behav Biomed Mater. 2009;2:433-443.

34. Tarwala R, Dorr LD. Robotic assisted total hip arthroplasty using the MAKO platform. Curr Rev Musculoskelet Med. 2011;4:151156. 